\title{
PROMOÇÁO DE REFLEXIVIDADE NA FORMAÇÁO INICIAL DOCENTE: O PAPEL DO PROFESSOR ORIENTADOR DE PESQUISA
}

\author{
Rita Buzzi Rausch \\ Ana Maria Falcão de Aragão Sadalla
}

\begin{abstract}
RESUMO
A formação inicial de professores, comumente, propõe princípios da prática investigativa como abordagem metodológica docente, constituindo-se em aprendizagem e construção reflexiva do professor. Nesta perspectiva, muitas instituições incluíram no currículo o Trabalho de Conclusão de Curso. Nesta atividade, investigamos os principais atributos do professor orientador ao desenvolvimento da reflexividade dos orientandos. Os sujeitos foram sete acadêmicas de Pedagogia. Os encontros de orientação foram gravados e transcritos e a apresentação oral da pesquisa videogravada. Foi solicitado para que cada acadêmica registrasse em portfólios, o processo de pesquisa vivenciado. Na realização de sua primeira pesquisa verificamos que as acadêmicas foram dependentes, apresentando medos e inseguranças frente ao novo. Os principais atributos da orientação à promoção da reflexividade das acadêmicas foram: mediação do conhecimento; auxílio na definição e compreensão da teoria; sinalização da necessidade de um olhar crítico frente ao fenômeno estudado; indicação de cuidados éticos à pesquisa; assunção de uma atitude indagativa; sinalização da incerteza do processo de pesquisa; animação do processo de aprendizagem das acadêmicas; inserção das acadêmicas em eventos científicos e solicitação do registro da pesquisa em portfólio. Este resultado vem ressaltar a importância da figura do orientador no processo de pesquisa à promoção da reflexividade docente.
\end{abstract}

\section{PALAVRAS-CHAVE}

Formação inicial de professores; Reflexividade; Iniciação à pesquisa; Papel do orientador de pesquisa

\section{PROMOTION OF REFLEXIVITY IN THE INITIAL EDUCATION OF TEACHERS: ROLE OF THE RESEARCH TUTOR}

\begin{abstract}
Principles of investigative practice are commonly proposed as teaching methodological approach in the initial education of teachers, which constitutes a reflexive construction and learning for the teacher. Under this perspective, a great number of institutions have included the End of Term Paper in their program. In this activity, it has been investigated tutors' main attributes for the development of their tutees' reflexivity. Seven academic learners from the Teacher Education Course were the subject of study. The meetings with tutors have been recorded and transcribed and the tutees' oral presentations have been video recorded. Each learner has been asked to produce a portfolio with data from their research processes. It has been observed that the students were very dependent during their first research, showing some fear and insecurity when facing new aspects. The man attributes in the orientation for the promotion of reflexivity from the learners were: knowledge mediation; help for definition and comprehension of theory; showing the need of a critical view of studied phenomena; indication for an ethical research; assumption for an inquisitive attitude; showing of uncertainty during the research process; increase of students' motivation during the learning process; applying for scientific events and requiring a portfolio for registering research data. The results found have demonstrated the importance of the presence of a tutor during the research process to promote on teachers.
\end{abstract}

\section{KEYWORDS:}

Initial education of teachers; Reflexivity; Scientific research initiation; Role of the research tutor 


\section{INTRODUÇÃO}

A constituição de um processo de reflexividade na formação de professores vem sendo, há algum tempo, defendido por alguns pesquisadores. Dentre eles, destacamos Schön (1983, 1987), Alarcão (2001, 2004), Sá-Chaves (2000, 2002) e Sadalla (2006, 2007), por defenderem perspectivas de formação de professores delineada a partir do pensamento do professor, saberes profissionais, desenvolvimento profissional docente, processos de tomada de consciência da/na/sobre/para a prática do professor. As sugestões de tais autores é que há necessidade de se pensar em uma formação reflexiva de professores, fomentando sua experiência em refletir, conduzindo a uma re-análise das crenças pedagógicas que alicerçam suas decisões cotidianas no ofício docente, da sua trajetória de vida, dos campos de conhecimento com os quais interagem, das finalidades e valores educativos que promovem, das condições sociais e históricas de sua própria profissão.

Entretanto, conforme Alarcão (1996) tornar-se um profissional reflexivo é possível, mas difícil, pois existem vários fatores que limitam sua efetivação no desenvolvimento profissional dos professores. Dentre esses fatores destaca: a falta de tradição em refletir; a resistência em mudar; a falta de condições e da exigência do processo de reflexão. Richert (apud ALARCÃO, 1996) constatou, em sua pesquisa, que existem vários fatores de ordem organizacional que impedem a reflexão na educação e que os formandos em nível de formação inicial têm dificuldade em refletir sem a ajuda de um colega ou de um formador. Schön (1987) também destacou a importância de ambientes de formação profissional prática que combinem ação e reflexão, propondo que os formandos sejam iniciados por um prático que os apóie e os oriente, ajudando-os a refletir. Assim, o pensamento reflexivo não se desenvolve espontaneamente, mas é um processo aprendido, e o formador tem um papel fundamental na sua promoção. Tal como indicou Alarcão (1996) o formador pode se utilizar de várias estratégias para promovê-la: perguntas pedagógicas; a observação de aulas; as narrativas; a análise de casos; o trabalho por projetos e a investigação-ação, o uso de portfólios. Conforme nossa pesquisa de tese (RAUSCH, 2008) acrescentamos nesse rol a pesquisa como mais uma alternativa significativa a este processo.

A defesa da pesquisa na formação de professores é bastante recente. Entretanto, tem se expandido consideravelmente nos últimos anos, tanto no Brasil quanto no exterior. "Ganha força no final dos anos 80 e cresce substancialmente na década de 1990, acompanhando os 
avanços que a pesquisa do tipo etnográfico e a investigação-ação tiveram nesse período" (ANDRÉ, 2001, p. 56).

Dos pesquisadores que vêm contribuindo com esse movimento no Brasil, destacamos André $(1994,2001)$ em que aponta o papel didático da pesquisa na relação entre saber docente e prática docente; Geraldi, Fiorentini e Pereira (1998) que compreendem a pesquisa como instrumento de reflexão coletiva sobre a prática; Lüdke $(2000,2001)$ que defende a combinação de pesquisa e prática na formação de professores. No exterior, vários autores já publicaram suas idéias em prol da pesquisa na formação docente. Dentre eles destacamos Stenhouse (1975) que foi pioneiro em afirmar que o ensino mais eficaz é baseado em pesquisa, concebendo o professor como investigador de sua própria prática; Carr e Kemmis (1988), alicerçados em uma teoria crítica, defendem a auto-reflexão coletiva e a investigaçãoação no sentido emancipatório; Zeichner (1993) salienta a inclusão da pesquisa na formação de professores, incentivando um trabalho conjunto entre a universidade e as escolas públicas, por meio da pesquisa colaborativa; Elliot (1996) destaca a investigação-ação como um movimento de reflexão para melhorar a prática.

Entretanto, a pesquisa ainda não figura como parte integrante nos cursos de formação de professores (LÜDKE, 2004). Muitos profissionais concluem sua licenciatura sem nunca ter vivenciado ou participado de um processo de pesquisa. Ressaltamos, também, que só mais recentemente, as políticas públicas voltadas à formação inicial de professores têm dado uma atenção mais específica à pesquisa. Destacamos a proposta de Diretrizes para a Formação Inicial de Professores da Educação Básica em Cursos de Nível Superior (2001), elaborada pelo Conselho Nacional de Educação que defende a pesquisa como elemento essencial na formação do profissional da educação. Ressalta a importância de uma postura reflexiva docente; o domínio de procedimentos de investigação científica pelo professor; a sistematização de informações; a análise de dados; o levantamento de hipóteses e verificação, no qual deverá produzir e socializar conhecimentos pedagógicos.

Coerente com tais diretrizes, algumas instituições de Educação Superior vêm incentivando a participação dos licenciandos em Programas de Iniciação Científica e adaptando o currículo da formação inicial de professores, incluindo, além de metodologias investigativas nas diferentes disciplinas que compõem a matriz curricular do curso, atividades diretamente voltadas à Iniciação à Pesquisa. O Trabalho de Conclusão de Curso surge na formação inicial buscando contribuir com essa diretriz. 
A atividade de TCC, em muitas instituições, tem o objetivo de inserir o acadêmico/professor em atividades de iniciação científica, desenvolvendo uma atitude investigativa/reflexiva como condição da docência. Nessa atividade, é comum os acadêmicos selecionarem um objeto de investigação e convidarem um professor da área para orientá-los. Compreendemos que o professor orientador exerce um papel fundamental à promoção da reflexividade de seus orientadores por meio da pesquisa. Neste sentido, neste artigo apresentamos alguns atributos do professor orientador que foram significativos à promoção da reflexividade de sete acadêmicas de Pedagogia.

\section{O PAPEL DO PROFESSOR ORIENTADOR DE PESQUISA}

Compreendemos que no processo de iniciação à pesquisa na formação de professores, o orientador jamais pode se dirimir do seu papel de formador. Formador este que conforme (SCHÖN, 1987) não se limita a ensinar, mas também facilitar a aprendizagem, conduzir o aluno de maneira que este possa construir e produzir conhecimento. A relação entre o formador e o formando deve permitir o diálogo, no qual o formador propõe desafios, questionando e aconselhando o formando a exercer sua criticidade. Vale ressaltar que isso não exclui a idéia do professor como alguém que possa expor teorias, discutir idéias, tirar dúvidas ou expor exemplos (SCHÖN, 1987) também na atividade de pesquisa. Em suma, “a atividade do formador articula o dizer com o escutar, a demonstração com a imitação e tem sempre subjacente a atitude de questionamento como via para a decisão" (ALARCÃO, 1996, p.19).

Conforme Marques (2001) ao objeto em si da orientação se agregam os seus aspectos instrumentais, como a indicação de conversas e leituras apropriadas, as orientações para uso de técnicas de trabalho adequadas, os pequenos segredos que só a prática compartilhada aponta. Ele desempenha um papel com os mesmos princípios de um educador que busca inserir o educando no fazer-se homem entre os homens, pesquisador entre os pesquisadores, ao mesmo tempo um sujeito singularizado de seus próprios saberes, com autonomia e competência. Dessa forma, compreendemos que o professor orientador de pesquisa passa a ser também, um supervisor do processo de desenvolvimento profissional e pessoal do orientando. Supervisão aqui entendida conforme Sá-Cháves uma prática acompanhada, interactiva, colaborativa e reflexiva que tem como objectivo contribuir para desenvolver no candidato a professor, o quadro de valores, de atitudes, de conhecimento, bem como as 
capacidades e as competências que lhe permitam enfrentar com progressivo sucesso as condições únicas de cada acto educativo.” (1994, p.150).

Nesse sentido, a supervisão implica uma relação bilateral entre o formador e o formando, reflexiva e crítica das práticas e teorias em constante mutação e inovação. Destaca ainda Sá-Chaves que:

\begin{abstract}
a supervisão [...] pressupõe um atento e abrangente olhar que contemple e atente ao perto e ao longe, ao dito e ao não dito, ao passado e às hipóteses de futuro, aos factos e às suas interpretações possíveis, aos sentidos sociais e culturais, à manifestação do desejo e à possibilidade/impossibilidade da sua concretização, ao ser e à circunstância, à pessoa e ao seu próprio devir (2000, p 127).
\end{abstract}

O objetivo final da supervisão, portanto, passa a ser a certeza de que se está contribuindo qualitativamente na formação dos acadêmicos, futuros professores, e a abertura de caminhos que motivem a reflexão e o crescimento profissional de cada sujeito, relacionando teoria e prática constantemente em sua atuação docente. Rompendo com os modelos tecnicistas e reprodutores, deseja-se que o supervisor/orientador assuma-se como um mediador da autoformação do orientando, responsabilizando-o e envolvendo-o ativamente no seu processo de desenvolvimento pessoal e profissional. Isso nos remete a defender o paradigma do inacabamento na formação dos professores (SÁ-CHAVES, 2004), no qual se entende que formar é sempre um verbo conjugado no gerúndio.

Portanto definimos o supervisor/orientador como uma pessoa mais experiente em pesquisa que juntamente com "o que é, o que faz, o que diz e o que sabe" (ALARCÃO, 2004, p 66) contribuirá para a formação de profissionais inovadores, flexíveis e intervenientes no seu próprio contexto de formação. Vieira (1993), referindo-se também ao papel do supervisor, destaca que este é um profissional com mais saber e experiência, receptivo por excelência ao professor que orienta, co-responsabilizando-se pelas suas opções, ajudando-o a desenvolverse para a autonomia através da prática sistemática da reflexão por meio da pesquisa.

Dessa forma, a missão que cabe ao supervisor reveste-se de extrema complexidade. Segundo Alarcão (1995, p 7), ele necessita demonstrar "uma atitude verdadeiramente reflexiva, ao lado de um saber tácito de experiência criticamente feita". Consequentemente, deverá ser:

inteligente, co-construtivo, inovador, flexível, psicológica e profissionalmente desenvolvido [...] ter visão superior [...] e ser capaz de actuar na complexidade dos contextos de formação, identificando e ajudando na solução dos problemas, sem se 

espera que tudo comande (ALARCÃO, 1996, p. 7).

Características estas complexas e nada fáceis de serem cumpridas na trajetória de um trabalho científico por parte do orientador, vista uma série de fatores que dificultam sua concretização, como por exemplo: tempo, espaço, formação, experiência em pesquisa.

\section{CAMINHOS INVESTIGATIVOS}

No primeiro semestre de 2006, orientamos quatro pesquisas de TCC: três foram realizadas em duplas e uma, individualmente. Dessa forma, acompanhamos um grupo de sete acadêmicas nas diferentes etapas da pesquisa: elaboração do projeto, coleta e análise dos dados, elaboração do relatório final e divulgação dos resultados. Realizamos encontros de orientação semanais nos quais discutíamos, em cada encontro, o que era necessário, pertinente e coerente com a trajetória de desenvolvimento de cada pesquisa. Utilizamos a audiogravação para o registro das falas ocorridas nesses encontros. As discussões de cada encontro foram gravadas em fita cassete para posterior transcrição e análise. A opção pela gravação dos encontros com as acadêmicas foi devida à possibilidade de, por meio das transcrições destas gravações, obtermos um registro ao qual fosse possível retornar para empreender a análise da pesquisa (SILVERMAN, 1994).

$\mathrm{Na}$ exposição do trabalho para uma banca examinadora, ao final do semestre, foi realizada também a videogravação para registrar a apresentação oral da síntese da pesquisa feita pelas acadêmicas, a apreciação do trabalho feita pelos professores avaliadores e o diálogo desencadeado nesta atividade. A filmagem foi feita por um profissional contratado, pois como orientadoras dos trabalhos apresentados, estivemos sempre participando como membros da banca. Além disso, compreendemos que por meio de um profissional experiente com o uso dessa tecnologia, haveria menos problemas com as filmagens, o que entendemos, requer sérios cuidados especiais com o som, a imagem, a luz. Conforme Loizos (2003), na gravação em vídeo, é relativamente fácil obter imagens, mas relativamente difícil ter uma boa qualidade de som.

No entanto, cabe destacar que tanto as acadêmicas como os professores avaliadores ficaram sabendo da filmagem, somente minutos antes de cada apresentação. Foi ali, no local da apresentação que solicitamos aos participantes (tanto às acadêmicas, como aos professores 
avaliadores) autorização para que a apresentação fosse filmada, não havendo restrições de ambos.

Cada acadêmica foi orientada a elaborar, também, um portfólio reflexivo, registrando os aspectos mais significativos vivenciados durante o desenvolvimento das diferentes etapas da pesquisa. O portfólio reflexivo, de acordo com Sá-Chaves (2005b), pode ser definido como uma coleção, seleção e organização do trabalho do futuro professor ao longo de certo tempo e que pode traduzir a evidência da sua auto-reflexão, aprendizagem e desenvolvimento pessoal e profissional.

As acadêmicas participantes já produziram portfólios em semestres anteriores na disciplina de Estágio Curricular Supervisionado. Naquele semestre, as acadêmicas foram orientadas a realizá-lo também na pesquisa do TCC como mais uma alternativa à promoção de sua reflexividade.

As análises empreendidas pautaram-se na constituição do processo de reflexividade de acadêmicas de Pedagogia por meio da análise dos níveis de lógica reflexiva promovidos na realização do TCC e analisar os principais atributos do professor orientador ao processo de reflexividade das acadêmicas.

\section{PRINCIPAIS ATRIBUTOS DA ORIENTAÇÃO DE PESQUISA AO PROCESSO DE REFLEXIVIDADE DAS ORIENTANDAS}

Destacamos abaixo, indicadores de atitudes da orientadora, manifestados nos registros e falas das acadêmicas, que contribuíram mais acentuadamente com o processo de reflexividade das acadêmicas:

a) Mediação do conhecimento: As acadêmicas, muitas vezes, pela inexperiência em pesquisa, viam na orientadora a pessoa que sabia tudo e esperavam muitas vezes que ela comandasse o processo. Algumas vezes as acadêmicas esperavam da orientadora, modelos, exemplos, diretrizes acabadas que, de certa forma, poderiam inibir sua criatividade. "Neste dia me encontrei com a professora Rita para montar minha apresentação para a Banca. Eu estava muito preocupada, pois, não me sentia segura sobre o que colocar nos slides. Quando cheguei à professora Rita, ela me perguntou se eu já tinha preparado um esboço da apresentação. Então coloquei para ela que eu não tinha preparado nada, pois tinha entendido que iríamos fazer juntas. Percebi que ela não gostou muito, pois, queria que eu levasse algo 
meio que já pronto" (PJ, 21/06/06). Desafiar as acadêmicas a criarem suas próprias produções, para que depois, por meio de um processo de mediação, a orientadora pudesse contribuir com a ampliação do conhecimento foi algo constante nessa trajetória. Portanto, exercer um processo de mediação do conhecimento, ao invés de transmissão do conhecimento cabe, também, ao processo de pesquisa, o que no nosso entender, contribui significativamente com o processo de reflexividade das acadêmicas.

b) Auxílio na definição do suporte teórico da pesquisa: A escolha de teóricos básicos e de obras centrais frente ao objeto em estudo é um processo necessário e fundamental em qualquer pesquisa. Essa escolha deve ser feita com cuidado pelo pesquisador em parceria com seu orientador. Geralmente o pesquisador iniciante, pela pouca experiência e falta de leituras, solicita auxilio do seu orientador. Foi o que aconteceu com as acadêmicas em análise. "S: Ah, tu tens assim uma dica de um livro do Vygotsky que a gente possa estar se aprofundando? (FSG1, 02/03/06)". André também entende que embora no processo é essencial o envolvimento ativo dos participantes, são imprescindíveis também as orientações e supervisão do professor. "É ele que orienta os alunos na busca de fontes, na escolha de métodos e na seleção de informações relevantes; é ele que os ajuda a sistematizar os dados e avaliar os resultados" (ANDRÉ, 2006, p 223). A orientadora, em alguns momentos, sentiu necessidade de direcionar a algumas leituras específicas. "R: Eu quero que vocês leiam esse texto aqui das novas diretrizes [...] que agora estão sendo incentivadas em nível nacional, que trazem um pouco das habilitações, tipo assim, porque o pedagogo pode atuar também em instituições não escolares" (FDJ1, 15/02/06). A escolha de materiais mais simples e fáceis de serem compreendidos também foi uma atitude que ocorreu com as acadêmicas em análise. Daí a importância do orientador justificar a importância de se ir à fonte primária da produção literária do objeto investigado, para não ficarmos na superficialidade da discussão científica, o que poderá vir a exigir maior reflexividade das acadêmicas. "R: Eu senti que tu ficaste mais em cima da obra da Rego e da Oliveira, e eu pedi pra você ler as obras do Vygotsky. Por que tu não fundamentaste teu texto a partir das próprias obras do Vygotsky? J: Porque o que eu consegui através do texto das duas, da Rego e da Oliveira, me fez compreender o que o Vygotsky dizia" (FJ2, 31/01/06). O empréstimo de livros do orientador para o orientando foi algo que também ocorreu. "Rita também nos emprestou um livro seu solicitando que lêssemos os capítulos 16, 17 e 26" (PD4, 13/03/06). Entendemos ser essa uma atitude importante quando sabemos da pouca circulação de algumas obras que consideramos pertinentes ao processo investigado. Levar ao aluno um referencial significativo e mais atualizado, no 
nosso entender, contribuiu para provocar alguns entendimentos mais elaborados acerca do conhecimento a ser construído.

c) Auxílio na compreensão das teorias, mostrando-se um professor leitor: Entretanto, não basta simplesmente indicar ou disponibilizar o referencial teórico a ser utilizado na pesquisa, mas, dialogar com o orientando acerca de suas interpretações sobre as leituras feitas "Aproveitei para fazer alguns questionamentos à Rita sobre algumas leituras feitas por mim e que estavam confusas em minha cabeça, o que foi muito interessante, pois me fez compreender muitas dúvidas que tinha" (PD4, 11/05/06). Na busca de contribuir com a formação do professor leitor por meio da pesquisa faz-se importante ao orientador demonstrar ser leitor. Coadunamos com a idéia de que a figura e modelo do professor orientador como leitor é uma das experiências escolares mais significativas no processo de formação dos alunos como leitores. Portanto, incentivar a leitura nesse processo, além das exigências da pesquisa, de forma prazerosa é um desafio para o orientador que busca contribuir com o desenvolvimento pessoal e profissional do orientando, pois a leitura é uma atividade que participa dessa formação, uma vez que lhe possibilita repensar e ressignificar sua visão de mundo, modificando sua forma de agir sobre a realidade. Dessa forma, o professor/orientador que pretende assumir um papel ativo na formação dos seus orientandos não pode restringir-se a ensinar a ler, mas deve preocupar-se em apresentar o mundo da leitura indicando livros, lendo para os orientandos, envolvendo-se na leitura, demonstrando entusiasmo e prazer em ler. Quando se fala em referencial teórico, é importante destacar que, por se tratar de um processo de iniciação à pesquisa, foi necessário introduzir as acadêmicas um contato mais aprofundado sobre obras de metodologia da pesquisa, para compreenderem as dimensões e exigências epistemológicas, metodológicas e técnicas de um trabalho científico. "R: e aqui tem uma obra bem interessante da André da (...) que fala sobre pesquisa em educação, abordagem qualitativa [...] vocês vão estudar um pouquinho isso, os tipos de pesquisa, abordagem de pesquisa qualitativa" (F2, 13/03/06). Em outro momento adiante ocorreu o questionamento acerca do entendimento pelas acadêmicas das questões metodológicas: "R: Mas, entendeste o que é uma pesquisa qualitativa? J: Sim. R: O que é uma pesquisa qualitativa?" (FJ2, 09:03:06)

d) Sinalização da necessidade de um olhar mais crítico das acadêmicas frente ao fenômeno estudado: a falta de leituras e a inexperiência em pesquisa levaram, muitas vezes, as acadêmicas a demonstrar uma visão ingênua frente à teoria estudada e aos dados 
analisados. Sinalizar alguns indicadores pelo orientador para avançar no processo de compreensão crítica do orientando fez-se necessário no desenvolvimento da pesquisa. "R: [...] Aqui uma questão que tu trazes e daí tu defendes muito o Ribeiro, o Brizola, assim, a gente sabe que foram políticos e por mais que eles tenham trabalhado em prol da escola de tempo integral eles não fizeram mais do que... J: A obrigação. R: Do que o dever deles. Então eu coloquei assim, visão ingênua, cuidado." (FDJ3, 22/05/06); "Aqui cabe uma análise, visão tecnicista de formação [...]." (FDJ3, 22/05/06). Em alguns momentos, após análise da orientação sobre a análise do orientando, este parecia despertar para uma análise mais crítica, indignando-se consigo mesmo por não ter se tocado disso antes. Essa discussão, provocou, em alguns momentos, meta-reflexões e ou meta-análises das acadêmicas “ J: Por isso que eu fico assim indignada. Eu coloco as coisas tudo ali, só que eu só vejo as coisas boas. Aí eu chego aqui e tu dizes por que eu não coloquei isso daqui, a falta de estrutura, a falta disso, a pouca formação, esse professor coloca isso. Mas, eu penso assim, como eu não enxerguei isso assim antes? Sabes, eu fico tão indignada com isso." (FDJ3, 22/05/06). Concordamos com Nóvoa (2002), quando afirma que hoje, o conhecimento se encontra disponível numa diversidade de formas e de lugares. Mas o momento do ensino (e da pesquisa) é fundamental para preparar a sua apreensão crítica. Desenvolver o espírito crítico como no ensino, na pesquisa também não se dá com monólogos expositivos por parte do orientador onde ele diz ao acadêmico o que deve criticar. Conforme Alarcão (2004), o desenvolvimento do espírito crítico faz-se no diálogo, no confronto de idéias e práticas, na capacidade de se ouvir o outro, mas também a capacidade de se ouvir a si próprio e de se autocriticar. Isso é possível num ambiente humano de compreensiva aceitação.

e) Reflexão acerca de alguns cuidados éticos na pesquisa: Contribuir com o desenvolvimento do conhecimento ético na formação do professor, por meio da pesquisa, deve ser uma preocupação constante do professor formador. Cada pesquisador social, embora iniciante, não deve esquecer nunca que a relação que se estabelece entre o pesquisador e o pesquisado é sempre uma relação social e política. Sá-Cháves (2001) destaca a importância que os processos formativos dos cidadãos adquirem nessa progressiva conscientização do compromisso ético com os valores do bem, da liberdade, da justiça, da solidariedade, de par com os valores, também inestimáveis, do desenvolvimento econômico, científico e cultural em todas as suas formas e manifestações. Acrescenta, também, que cabe à educação a parte fundamental da tarefa de conciliar crescimento econômico e desenvolvimento social e de assegurar os valores da cidadania plena. Na trajetória do desenvolvimento das pesquisas aqui 
analisadas, a dimensão ética foi um processo discutido e praticado. Destacamos uma reflexão que surgiu a partir da dificuldade enfrentada pelas acadêmicas/pesquisadoras na aceitação de suas presenças nas escolas campo de pesquisa. "R: É na realidade a questão é a seguinte: esse cuidado que nós temos que ter como pesquisadoras. Porque na realidade existem muitos pesquisadores que realmente usam esses espaços com o único objetivo de coletar dados para os seus trabalhos, suas pesquisas, e não contribuem, não retornam a instituição, contribuindo com uma nova forma de ver o objeto investigado, com uma mudança social.[...] A iniciativa de vocês já se posicionarem e querer dar um retorno para a instituição, isso é fundamental" (FGS2, 04/04/06).

Os desafios que se colocam à formação são [...] os desafios à reflexão pessoal e coletiva, enquanto processo e instrumento de conscientização progressiva, de desenvolvimento continuado e partilhado, de persistência na investigação constante, enquanto fonte de novos informes, de crença, de algum modo sublime, na hipótese de o homem vir a descobrir-se e encontrar-se com a sua própria humanidade (SÁCHÁVES, 2001, p. 89).

Discutir a responsabilidade das acadêmicas enquanto pesquisadoras, para além da execução e sistematização do trabalho científico, assumindo um compromisso com os espaços investigados, com os sujeitos envolvidos e com a sociedade de uma maneira geral é fundamental, para profissionais que queremos críticos, criativos e éticos.

f) Assunção de uma atitude indagativa: Conforme Alarcão (2004), pelo questionamento, tudo é susceptível de vir a ser mais bem compreendido, mais assumidamente aceite ou rejeitado. Essa atitude de questionar, no intuito das acadêmicas sentirem-se mais seguras dos percursos a serem seguidos, argumentando suas próprias escolhas, ampliando seu processo reflexivo foi algo que ocorreu durante a trajetória da pesquisa. "O que vocês querem dizer com isso? Expliquem para mim" (FGS 20/03/06). Ao questionar, o professor orientador/supervisor, além de se preocupar com aspectos imediatos da pesquisa, precisa assumir uma preocupação com a formação do orientando, e portanto, seus questionamentos precisam, também, ter uma intencionalidade formativa "R: Será que o estágio é aplicação da teoria? Será que a teoria se aplica na prática? Você estuda a teoria antes para depois aplicar na prática? Eu gostaria que vocês pensassem sobre isso. Como é que vocês entendem isso? ” (FAD3, 23/03/06).

g) Sinalização da incerteza do processo de pesquisa: Formar e preparar as acadêmicas para o incerto, para a mutação constante é uma necessidade na formação de professores. 
Demonstrar isso por meio da pesquisa se tornou um processo mais fácil e compreensível por parte das acadêmicas, pois é inerente a esse processo lidar com a relatividade do conceito de verdade. "R: Precisamos ser humildes, pois como humanos que somos estamos propensos ao erro" (FAD3, 23/03/06). Conforme Sá-Cháves (2001) um dos desafios da formação de professores é

aceitar as condições de incerteza que caracterizam toda a atividade humana, ditando correspondentes condições de diversidade, de heterogeneidade e de imprevisibilidade impeditivas da pré-definição de respostas, da sua modelação estandartizada, da sua execução acrítica e independente dos fatores contingenciais de cada situação e/ou momento histórico (p. 89).

Compreender a complexidade da pesquisa por meio da crise que ora a ciência vive é fundamental para um pesquisador consciente de seus atos e repercussões na sociedade. De acordo com Morin (2003) o progresso das certezas científicas produz o progresso da incerteza, uma incerteza boa que nos liberta de uma ilusão ingênua e nos desperta de um sonho lendário: é uma ignorância que se reconhece como ignorância.

\section{h) Animação do processo de aprendizagem das acadêmicas por meio da pesquisa: No} desenvolvimento das pesquisas aqui analisadas, ocorreu, em alguns momentos, certo desânimo das acadêmicas, frente às dificuldades que enfrentaram pela complexidade do processo, pela inexperiência em pesquisa e pela absorção do cotidiano profissional. "A elaboração e execução de um TCC é bem desgastante, principalmente quando se trabalha o dia inteiro num lugar onde se encontram muitos problemas para resolver. A cabeça fica cheia e a concentração muitas vezes se torna difícil. É por isso que precisamos durante essa fase estar recebendo mensagens de ânimo, mensagens que nos fazem perceber o quão importante é o nosso trabalho; precisamos ser incentivadas a cada dia a fazer o melhor" (PS, 05/06/06). O incentivo e apoio constante do orientador é fundamental para que o processo avance a contento. "Não posso deixar de falar que as sensações ao sair da sala da orientadora foram várias. Às vezes saímos um pouco desesperadas por ouvir tudo o que teríamos pela frente, às vezes um pouco angustiadas por saber que ainda tínhamos que melhorar bastante, mas, muitas das vezes saímos animadas para continuar o trabalho e nos esforçar um pouco mais" (PS, 20/05/06). Conforme Alarcão (2004) os professores são estruturadores e animadores das aprendizagens. Legrand (apud MARQUES, 2001) também aponta para o papel ativo do orientador, que ele denomina de animador, em duas fases: a fase da exploração onde estimula a produção do material da pesquisa colocando questões concretas de forma a decompor a 
densidade das experiências e práticas; e a fase das hipóteses e da interpretação: armam-se questões mais densas e coerentes entre si, novas pistas a serem exploradas, o enriquecimento com outros pontos de vista. Conforme Marques (2001) de movimento de desconstrução/descentração e de reconstrução/enriquecimento pela inserção em quadros mais amplos de análise.

i) Inserção das acadêmicas em eventos científicos: $O$ orientador exerce um importante papel na inserção dos acadêmicos, iniciantes em pesquisa, em processos científicos. "Uma coisa que eu quero estar dizendo a vocês. Eu gostaria muito que vocês participassem, em um primeiro momento, em forma de poster no Seminário das Licenciaturas. As inscrições estão em aberto até dia 10/04/06" (FDJ2, 20/03/06). Ficou evidenciado o quanto a elaboração de pôsteres, resumos e artigos, a participação em palestras e a exposição oral do trabalho, interagindo com outros pesquisadores, contribuiu com o processo de reflexividade das acadêmicas. Desde o início, é preciso incutir que a socialização e publicação dos resultados é uma etapa da própria pesquisa. Sem socializar e publicar os resultados a pesquisa não conclui seu objetivo.

j) Solicitação do registro da pesquisa em portfólio: Esta, talvez, foi a estratégia mais significativa solicitada pela orientadora para ser elaborada no percurso da realização da pesquisa pelas acadêmicas, pois a grande parte das reflexões metacríticas e metapráxicas se consolidaram via esse instrumento. Reforçamos mais uma vez a importância de utilizarmos essa estratégia pedagógica, também no desenvolvimento da pesquisa, quando queremos formar professores reflexivos. Essa estratégia, conforme Sá-Cháves (2005) responde com grande qualidade a esta filosofia de formação pois procura evidenciar o fluir dos processos subjacentes ao modo pessoal como cada qual se apropria singularmente da informação, reconstruindo seu conhecimento pessoal. Foi perceptível nos registros das acadêmicas feitos no portfólio que elas dialogaram consigo mesmas, organizando sua aprendizagem e desenvolvimento por meio dele, encontrando motivação e sentido naquilo que faziam. "Os formadores de professores têm uma grande responsabilidade na ajuda ao desenvolvimento desta capacidade de pensar autônoma e sistematicamente" (ALARCÃO, 2004, p.46). O uso do portfólio mostrou-se uma alternativa significativa neste trabalho. 


\section{CONSIDERAÇÕES FINAIS}

Os professores são autores e atores fundamentais à mudança educacional que buscamos. Defendemos a importância da sua formação para que possam intervir curricularmente ao nível de seus múltiplos papéis e funções, não só com a informação científica precisa e atualizada, mas, também, com todas as competências estruturantes do seu pensamento e da sua ação que intentam desenvolver nos seus próprios alunos. Este é nosso grande desafio hoje, enquanto formadores de professores. Para isso precisamos selecionar estratégias pedagógicas que possibilitem o desenvolvimento dessas dimensões.

Formamos professores ao mesmo tempo em que nos formamos, e também em que a sociedade muda e se altera a configuração da universidade. A vida é movimento, é processo, assim como a educação, o conhecimento. Historicamente, ao nos distanciarmos dos cânones da modernidade, abrimos mão das certezas e vivemos a dimensão da provisoriedade. Nesse sentido, o testemunho da procura exigente, do saber pesquisar, pode ser um dos legados que podemos deixar aos nossos acadêmicos.

O investimento na formação de professores precisa superar a qualificação meramente técnica, que ainda domina o cenário da formação dos professores. Formar um educador não é só ensinar-lhe conhecimentos acadêmicos, pois isso não garante a fecundidade de sua atuação docente, que precisa impulsionar mudanças na sociedade pela transformação das pessoas que aprendem a partir de sua intervenção. Essa formação precisa ser também política para que o

professor possa se sensibilizar frente às condições histórico-sociais nas quais ele e seus alunos estão inseridos. Essa formação precisa ser efetivamente reflexiva contribuindo para que o professor possa reavaliar permanentemente sua atuação buscando direcioná-la rumo aos princípios de humanização e emancipação da sociedade, do ser humano e da educação.

Se perguntássemos a vários professores se eles se vêem no papel de pesquisadores, certamente a resposta da grande maioria seria negativa. A razão desse fato está na tradicional distância que sempre houve entre os papéis do professor e do pesquisador. O professor ao longo de nossa história educacional foi tradicionalmente aquele que agia na sala de aula, na tentativa de colocar em prática o que aprendeu com o pesquisador. Acreditamos que todo professor pode e deve ser pesquisador, pois somente a aliança entre teoria e prática provocará os resultados que almejamos, tanto na formação dos professores como na educação de uma 
maneira geral. Nessa pesquisa buscamos identificar os fios que se tecem entre pesquisa e reflexividade na formação inicial de professores, buscando aproximar os papéis do professor reflexivo e do professor pesquisador, dando um destaque ao processo da reflexividade desenvolvido por meio da pesquisa.

Percebemos que os níveis de lógica reflexiva mais complexos aconteceram ao longo do desenvolvimento da pesquisa das acadêmicas, entretanto, foi frente à compreensão da teoria em estudo e da necessidade de relacioná-la aos dados em suas análises que estes níveis foram mais acentuados. Isto pode revelar a importância da teoria relacionada à prática na formação inicial de professores quando busca promover a reflexividade dos educandos e a pesquisa como uma atividade acadêmica que necessariamente direciona a tal relação. Percebemos que a necessidade de articular teoria e dados na pesquisa foi um processo que provocou um salto qualitativo na forma de refletir das acadêmicas. Esse movimento continuado, sistemático e crítico permitiu sugerir que a indissociabilidade entre teoria e dados induz a uma nova reflexão, a uma re-análise constante, o que resulta em nova teoria. Isto nos leva a crer que sem construtos teóricos relacionados à prática torna-se difícil o desenvolvimento do processo de reflexividade.

Ao investigar e analisar os atributos do professor orientador à promoção do processo de reflexividade das alunas, acreditamos que as acadêmicas, na realização de sua primeira pesquisa, foram muito dependentes, apresentando medos e inseguranças frente ao novo. Frente a isso, a orientação exerceu um papel fundamental em não colocá-las em um processo de desistência ou de acomodação. Evidenciamos que o orientador exerce papel fundamental no desencadeamento do processo reflexivo dos orientandos em cada etapa da pesquisa. Fazer, pensar sobre, refletir criticamente e coletivamente, refazer, refletir novamente deve ser um processo constante na realização da pesquisa. Nesse sentido, a formação para o professor orientador também se faz necessária.

A orientação é um processo rico de aprendizagem tanto para o orientador, quanto para o orientando, que como sujeitos em transformação, vão alterando as suas visões sobre o processo de pesquisar e de ensinar. As relações interpessoais estabelecidas entre nós foram provocando um desejo de avançar, de melhorar, de mudar, de modo que fomos tornando-nos reflexivas coletivamente e co-partícipes do processo. Os encontros de orientação foram ganhando identidade, nos quais as discussões feitas repercutiam em cada acadêmica 
individualmente, entretanto, as reflexões de maneira dialógica, dialética e partilhada nos direcionavam a um olhar para o mundo com uma maior unidade.

Frente às respostas obtidas, impulsionamo-nos a deixar algumas sugestões e recomendações. Nesse sentido, nossas recomendações voltam-se a afirmar que antes de querermos professores reflexivos é necessário desenvolvermos universidades reflexivas e termos formadores de professores reflexivos. É fundamental que os formadores de professores também sejam pesquisadores e compreendam a pesquisa como algo imprescindível quer ao seu desenvolvimento profissional, quer ao de seus acadêmicos. A pesquisa precisa ser compreendida como uma atividade que visa à produção do conhecimento e que, por meio dela, aprende-se a ordenar as próprias idéias, a olhar e pensar a realidade cientificamente utilizando-se da informação teórica e factual para isso.

Em suma, a questão básica é analisar se o professor orientador contribui ao desenvolvimento da reflexividade dos alunos, tornando-os profissionais capazes de construir, produzir conhecimento contextualizado a partir das teorias em que se fundamenta, sendo responsáveis pelas consequiências do ato de ensinar cujos resultados acadêmicos e sociopolíticos serão observados nos autoconceitos dos alunos, em seu desenvolvimento intelectual e na possibilidade de gerar melhor qualidade de vida pessoal e coletiva.

\section{REFERÊNCIAS}

ALARCÃO, I. (Org.). Formação reflexiva de professores: estratégias de supervisão. Porto: Editora Porto, 1996.

ALARCÃO, I. (Org.). Escola reflexiva e nova racionalidade. Porto Alegre: Artes Médicas, 2001.

ALARCÃO, I. Professores reflexivos em uma escola reflexiva. São Paulo: Cortez, 2004.

ANDRÉ, M. O papel da pesquisa na formação de professores. In: REALI, A.M.R.; MIZUKAMI, M.G.N. Formação de professores, tendências atuais. São Carlos: EDUFSCAR, 1994.

ANDRÉ, M. Pesquisa, formação e prática docente. In: ANDRÉ, M. ; LÜDKE, M., O papel da pesquisa na formação e na prática dos professores (Org.). Papirus: São Paulo, 2001. 


\begin{abstract}
ANDRÉ, M. Ensinar a pesquisar... Como e para quê? In: SILVA, A. M.M. et al (Org.). Educação formal e não formal, processos formativos e saberes pedagógicos: desafios para a inclusão social. Recife, ENDIPE, 2006.
\end{abstract}

BRASIL. Conselho Nacional de Educação. Proposta de diretrizes para a formação inicial de professores da educação básica em cursos de nível superior. 2001.

CARR, W.; KEMMIS, S. Teoria crítica de la enseñanza: la investigación-acción en la formación del professorado. Barcelona: Martínez Roca, 1988.

ELLIOT, J. El cambio educativo desde la investigaciós-acción. Madri: Morata, 1996.

GERALDI, C.M.G.; FIORENTINI, D.; PEREIRA, E.M. de A. (Org.). Cartografias do trabalho docente. Campinas: Mercado das Letras, 1998.

LOIZOS, P. Vídeo, filme e fotografias como documentos de pesquisa. In: BAUER, M. W; GASKELL, G. Pesquisa qualitativa com texto, imagem e som: um manual prático. Petrópolis: Vozes, 2003.

LÜDKE, M. A pesquisa e o professor da escola básica: que pesquisa, que professor? In: CANDAU, V. M. (Org.). Ensinar e aprender: sujeitos, saberes e pesquisa. Rio de Janeiro: DP\&A, 2000.

LÜDKE, M. et al. O professor e a pesquisa. Campinas: Papirus, 2001.

LÜDKE, M. Investigando sobre o professor e a pesquisa. In ROMANOWSKI, J.; MARTINS, P.; JUNQUEIRA, S. (Org.). Conhecimento local e conhecimento universal: pesquisa, didática e ação docente. Curitiba, Champagnat, 2004.

MARQUES, M. O. Escrever é preciso: o princípio da pesquisa. Ijuí: Unijuí, 2001.

NÓVOA, A. O espaço público da educação: imagens, narrativas e dilemas. In: PROST, A. et al. Espaços de educação: tempos de formação. Lisboa: Fundação Calouste Gulbenkian, 2002.

RAUSCH, R. B. A reflexividade promovida pela pesquisa na formação inicial de professores. 180f. 2008. Tese (Doutorado) - Faculdade de Educação, Universidade Estadual de Campinas, Campinas, 2008.

SÁ-CHAVES, I. Formação, conhecimento e supervisão. Contributos nas áreas da formação de professores e de outros profissionais. Aveiro: Universidade de Aveiro, 2000.

SÁ-CHAVES, I. Informação, formação e globalização: novos ou velhos paradigmas? In: ALARCÃO, I. (Org). Escola reflexiva e nova racionalidade. Porto Alegre: Artes Médicas, 2001.

SÁ-CHAVES, I. A construção de conhecimento pela análise reflexiva da práxis. Lisboa: Fundação Calouste Gulbenkian ; Ministério da Ciência e da Tecnologia, 2002. 
SÁ-CHAVES, I; PAIXÃO, F; CACHAPUZ, A. Desafios da complexidade e novas tendências de reconceptualização curricular. Série Estudos - UCDB, Campo Grande , n.15, p. 11-36, jan/jun, 2003.

SÁ-CHAVES, I. Formação de professores: encruzilhadas e desafios. Conferência proferida no Curso Desenvolvimento profissional e competência reflexiva: estratégias metacognitivas de co-construção de conhecimento. Promoção GEPEC: UNICAMP, 11 a 15 de julho de 2005a .

SÁ-CHAVES, I. Formação e desenvolvimento pessoal e profissional: o uso de portfolio reflexivo. Conferência proferida no Curso Desenvolvimento profissional e competência reflexiva: estratégias metacognitivas de co-construção de conhecimento. Promoção GEPEC: UNICAMP, 11 a 15 de julho de 2005b.

SÁ-CHAVES, I. (Org.). Os "portfolios" reflexivos (também) trazem gente dentro: reflexões em torno do seu uso na humanização dos processos educativos. Porto: Porto Editora, 2005c.

SÁ-CHAVES, I. Notas de orientação individual. Pós-doutoramento de Ana M. F. de Aragão Sadalla. Aveiro: Universidade de Aveiro, abril e maio de 2007.

SADALLA, A.M.F. de A. Construindo uma escola reflexiva: o que a psicologia tem a ver com isso? In. VICENTINI, A. A. F.; SANTOS, I. H. dos; ALEXANDRINO, R. (Org.). O coordenador pedagógico: práticas, saberes e produção de conhecimentos. Campinas: UNICAMP/FE, 2006.

SADALLA, A. M. F. De A. Constituição da reflexividade docente: indícios de desenvolvimento profissional coletivo. Relatório pós-doutoral. Aveiro: Universidade de Aveiro, 2007.

SCHÖN, D. The reflective practitioner. Londres: Temple Smith, 1983.

SCHÖN, D. Educando o profissional reflexivo. Porto Alegre: Artes Médicas, 1987.

SILVERMAN, D. Interpreting qualitative data. SAGE Publications, 1994.

STENHOUSE, L. An introduction to curriculum research and development. London: Heinemann, 1975.

ZEICHNER, K. M. A formação reflexiva de professores: idéias e práticas. Lisboa: Educa, 1993. 
RITA BUZZI RAUSCH

Pedagoga. Doutora em Educação. Atua como docente e pesquisadora no curso de Pedagogia na Fundação Regional de Blumenau (FURB) - SC E-mail: rausch@furb.br

ANA MARIA FALCÃO DE ARAGÃO SADALLA

Psicóloga. Doutora em Educação. Docente do

Departamento de Psicologia Educacional da Faculdade de Educação da Universidade

Estadual de Campinas (UNICAMP).

E-mail: anaragao@terra.com.br

Recebido em: 06/03/2008

Publicado em: 20/06/2008 